\title{
The effect of shoulder injury prevention program on glenohumeral range of motion and upper extremity performance in adolescent throwers: A pilot study
}

Authors' Contribution: A Study Design B Data Collection C Statistical Analysis D Data Interpretation E Manuscript Preparation F Literature Search G Funds Collection

\author{
Gamze Cobanoglu ${ }^{1}$ ABCDEF, Hasan Aka ${ }^{2 A B}$, Nevin A. Guzel ${ }^{1}$ AD \\ ${ }^{1}$ Department of Physiotherapy and Rehabilitation, Faculty of Health Sciences, \\ Gazi University, Ankara, Turkey \\ 2 Department of Coaching Education, Faculty of Sport Sciences, \\ Niğde Ömer Halisdemir University, Niğde, Turkey
}

\section{abstract}

Background: The Oslo Sports Trauma Research Center (OSTRC) Shoulder Injury Prevention Program is an exercise program developed to increase the internal rotation (IR) range of motion (ROM), external rotator muscle strength and scapular muscle strength and to improve kinetic chain involvement and thoracic mobility. The purpose of this study is to investigate the effect of this program on glenohumeral ROM and upper extremity functional performance in adolescent throwers.

Material and methods:

Conclusions:

article details

Article statistics:

Full-text PDF:

Copyright

Indexation:

Conflict of interests: Corresponding author:

Open Access License:

Ten adolescent throwers (discus, shot put and javelin throwers) were involved in the study. The OSTRC Shoulder Injury Prevention Program was applied three times a week for 8 weeks as a part of warm-up. Glenohumeral IR and external rotation (ER) ROM were evaluated with a goniometer. The Closed Kinetic Chain Upper Extremity Stability Test (CKCUEST) was used to evaluate the upper extremity functional performance.

It was found that there was a statistically significant difference in the dominant side IR ROM and CKCUEST between the pre-test and post-test $(p<0.05)$; however, there was no difference in terms of other parameters $(p>0.05)$.

This study shows that the glenohumeral IR ROM and upper extremity functional performance increases after the 8-week OSTRC Shoulder Injury Prevention Program. For these purposes, physiotherapists and trainers can include this program in their training programs.

Received: April 2021; Accepted: August 2021; Published: December 2021

http://www.balticsportscience.com

○ Gdansk University of Physical Education and Sport, Poland

Celdes, Clarivate Analytics Emerging Sources Citation Index (ESCI), CNKI Scholar (China National Knowledge Infrastructure), CNPIEC, DOAJ, EBSCO - Central \& Eastern European Academic Source, EBSCO - SPORTDiscus, EBSCO Discovery Service, Google Scholar, Index Copernicus, J-Gate, Naviga (Softweco, Primo Central (ExLibris), ProQuest - Family Health, ProQuest - Health \& Medical Complete, ProQuest - Illustrata: Health Sciences, ProQuest Nursing \& Allied Health Source, Summon (Serials Solutions/ProQuest, TDOne (TDNet), Ulrich's Periodicals Directory/ ulrichsweb, WorldCat (OCLC)

This research received no specific grant from any funding agency in the public, commercial, or not-for-profit sectors. Authors have declared that no competing interest exists.

Gamze COBANOGLU, PT, MSc; Gazi University, Faculty of Health Sciences, Department of Physiotherapy and Rehabilitation, Besevler/ Ankara; Postal address: Emek mah. Bişkek Cad. 6. Cad. No:2 06490 Çankaya/ANKARA; e-mail: fztgamze7@gmail.com; ORCID: 0000-0003-0136-3607 Derivatives 4.0 International (https://creativecommons.org/licenses/by-nc-nd/4.0/), which permits use, distribution, and reproduction in any medium, provided the original work is properly cited, the use is non-commercial and is otherwise in compliance with the license. 


\section{INTRODUCTION}

Throwing events in track and field are among the oldest sporting events in recorded history. In most sports, throwing requires generation of maximum force in a short time, and throwers become more prone to high stress tendon, muscle, ligament, and joint injuries. Throwing athletes are also at risk of repetitive stress injuries due to the precision required to succeed in throwing and the high number of repetitions required to maintain good performance [1].

While shoulder rotation during a throwing event typically involves large external rotation (ER), internal rotation (IR) is limited [2]. Increased ER-decreased IR range of motion in the throwing arm of overhead throwing athletes leads to adaptive changes, such as hypermobility of the anterior capsule and hypomobility of the posterior capsule [1]. In particular, the tension in the posterior capsule due to limited IR leads to an increase in anterior translation and disintegration force during glenohumeral flexion [2]. This can lead to subluxation, which is considered as the primary mechanism of shoulder pain in throwers [1]. During throwing, the glenohumeral, acromioclavicular and sternoclavicular joints are exposed to axial, translational and distraction forces. This can lead to overuse injuries, such as muscle strains, degenerative joint disease, ligament sprains, instability, and sometimes more acute injuries, such as dislocations. In addition, the strength training regimen required in throwing puts athletes at risk of injury to the joints mentioned above [3]. As a result of this strength training regimen and throwing biomechanics, the upper extremities become more susceptible to injury compared to other sports disciplines [4]. For all these reasons, prevention of shoulder injuries with structured approaches should be an important focal point [5]. Identifying risk factors and developing strategies to prevent injuries based on these risk factors are key components to prevent injuries in athletes [6].

The Oslo Sports Trauma Research Center (OSTRC) shoulder injury prevention program is an exercise program developed to increase IR range of motion, external rotator muscle strength and scapular muscle strength and to improve kinetic chain involvement and thoracic mobility $[7,8]$. In a randomized controlled trial of 660 elite handball players, the OSTRC Shoulder Injury Prevention program was applied three times a week as a part of the handball warmup. As a result of the study, it was found that the risk of shoulder problems in the training group was $28 \%$ lower than in the control group. Therefore, it was stated that it should be added to training programs in order to reduce the risk of injury [7]. Studies have reported that making this program more available and common will be beneficial [9]. Although there are studies investigating the effectiveness of the OSTRC Shoulder Injury Prevention Program in handball players in the literature, there are no studies which investigate the effect of this program on the range of motion and upper extremity functional performance in track and field throwing athletes. Therefore, the purpose of this study is to investigate the effect of OSTRC Shoulder Injury Prevention Program on glenohumeral joint rotation range of motion and upper extremity functional performance in adolescent track and field throwing athletes.

\section{MATERIAL AND METHODS}

\section{DESIGN}

This pilot study was conducted at Gazi University Faculty of Health Sciences Department of Physiotherapy and Rehabilitation. The ethical approval was obtained before the study Gazi University Ethics Committee Date: 14/07/2020, Number: 91610558-604.01.02-, Study Code No: 2020-375). All participants gave their written informed consent prior to participation in the study. The goniometric measurements and upper extremity performance of the throwers were evaluated by an experienced physiotherapist before starting the prevention program. The OSTRC Shoulder Injury Prevention Program was applied to the throwers for eight weeks by coaches. The measurements were repeated 2 days after the 8 -week program by the same physiotherapist. 


\section{PARTICIPANTS}

Adolescent throwers (discus, shot put and javelin throwers) who did not experience any injury to their upper extremities in the last 6 months were involved in the study. Those who had upper extremity surgery, upper extremity deformity and neurological problems or systemic diseases were excluded from the study. The first evaluations of 13 throwers who agreed to participate in the study were received. As 3 throwers discontinued the study after the first evaluation, the study was completed with 10 throwers (6 males and 4 females). Demographic information of the participants is presented in Table 1. The demographic information, dominant sides, age when they started sports and weekly training hours of the throwers was received and recorded.

Table 1. Demographic information of the participants

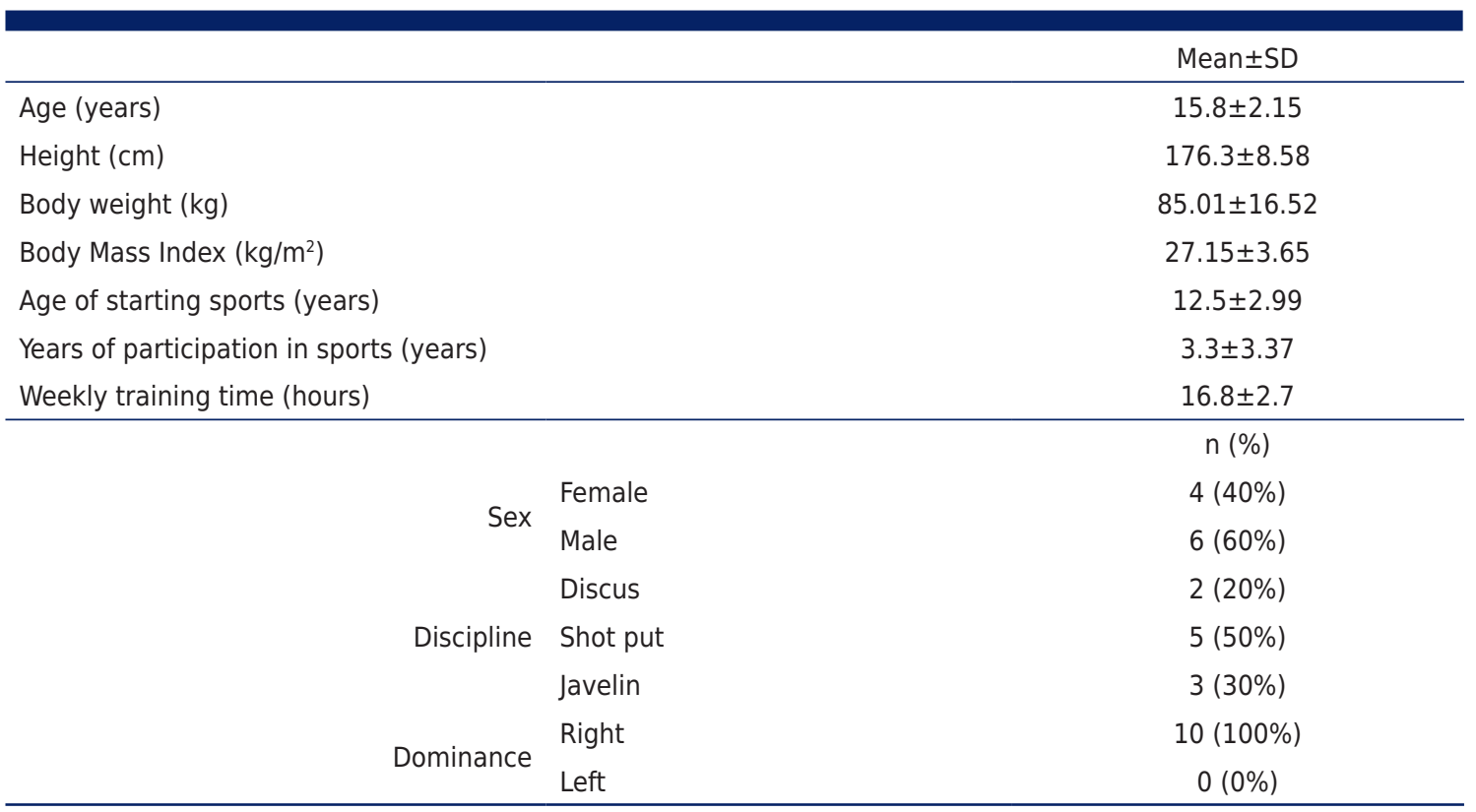

SD: Standard Deviation

\section{RANGE OF MOTION}

Glenohumeral joint IR and ER range of motion were evaluated by a goniometric measurement by an experienced physiotherapist in the supine position. Measurements were performed with the shoulder at $90^{\circ}$ abduction and the elbow at $90^{\circ}$ flexion. The pivot was placed on the olecranon for rotation measurements. While the fixed arm was kept parallel to the treatment table and the floor, the moving arm followed the 3rd metacarpal bone at the midpoint of the radius and ulna. During the measurement care was taken that there was no change in the $90^{\circ}$ abduction and no flexion extension and elevation movements. The movement was stopped at the range where we saw the shoulder move to prevent compensation and the active range of motion was recorded in degrees. Subsequently, all measurements were repeated for the other extremity [10].

\section{UPPER EXTREMITY PERFORMANCE}

CKCUEST was used to evaluate the throwers' upper extremity performance. CKCUEST has been shown in previous studies to be a measure of moderate to excellent reliability for adolescents [11]. CKCUEST was performed by an experienced physiotherapist for men and women in the same position. Two pieces of tapes were placed on the floor parallel to each other at $90 \mathrm{~cm}$ intervals. In the starting position of the test, the thrower's hands were placed on a piece of tape in the push-up position. The thrower was asked to move their hands from one tape to the other as quickly as possible. The number of times the thrower touched lines 
in 15 seconds was recorded. Each thrower took three tests, one of which was a warm-up test. A 45-second rest period was allowed between the tests. In data analysis, the mean of the two tests was calculated [12].

\section{Injury Prevention Exercise Program}

The OSTRC Shoulder Injury Prevention Program was applied to the throwers three times a week during the warm-up period of their training program by coaches. The OSTRC Shoulder Injury Prevention Program consists of five exercises (15 in total) with different variations and levels [7]. The program took about 15 minutes to complete. Two measurements were performed by an experienced physiotherapist one day before the initiation of the exercise program and 2 days after the 8-week program.

\section{STATISTICAL ANALYSIS}

SPSS 22 package software was used to analyze the data. In the evaluation of the data, descriptive statistics, mean, and standard deviation were provided for those with normal distribution, and median and interquartile range were provided for those without normal distribution. The Wilcoxon test was used to determine the difference between the pre-test and post-test results of the throwers. The significance level in the study was accepted as $p<0.05$. The effect sizes of the groups were evaluated according to Cohen's $d$ standards within the pre-end differences. Effect size results were interpreted as small (0.2), medium $(\geq 0.5)$ or large $(\geq 0.8)$, according to the guidelines [13].

\section{RESULTS}

Based on the examination of the results, it was found that there was a statistically significant difference in terms of the dominant side IR range of motion and CKCUEST $(p<0.05$, Table 2 ), and that there was no difference in terms of other parameters ( $p>0.05$, Table 2 ). It was demonstrated that the dominant side IR range of motion and CKCUEST scores increased in the post-test compared to the pre-test.

Table 2. Pre-test and post-test comparison of glenohumeral range of motion and upper extremity performances of adolescent throwers

\begin{tabular}{llccccc}
\hline & $\begin{array}{c}\text { Pre-test } \\
\text { (Median / IQR) }\end{array}$ & $\begin{array}{c}\text { Post-test } \\
\text { (Median / IQR) }\end{array}$ & $\begin{array}{c}\text { Change } \\
\text { (Median / IQR) }\end{array}$ & p & Effect size \\
\hline Dominant side & ER (degree) & $115(110 / 119)$ & $105(100 / 110)$ & $-9.5(-15 / 0)$ & 0.159 & 0.61 \\
& IR (degree) & $77.5(65 / 80)$ & $82.5(75 / 105)$ & $12.5(5 / 25)$ & $\mathbf{0 . 0 0 8 *}$ & 1.23 \\
& TROM (degree) & $190(185 / 195)$ & $185(180 / 210)$ & $3(-10 / 15)$ & 0.314 & 0.36 \\
\hline Non-dominant & ER (degree) & $106.5(90 / 110)$ & $100(95 / 115)$ & $2.5(-8 / 10)$ & 0.389 & 0.23 \\
& IR (degree) & $73.5(70 / 95)$ & $87.5(80 / 95)$ & $10(10 / 15)$ & 0.050 & 0.78 \\
& TROM (degree) & $180(175 / 195)$ & $195(185 / 200)$ & $15(0 / 20)$ & 0.106 & 0.68 \\
\hline CKCUEST (number of touches) & $20.5(17 / 22)$ & $24(24 / 27)$ & $4(3 / 6)$ & $\mathbf{0 . 0 0 7 *}$ & 2.00 \\
\hline
\end{tabular}

TROM: Total Range of Motion, CKCUEST: Closed Kinetic Chain Upper Extremity Stability Test, IQR: Inter Quantile Range, $* p<0.05$

\section{DISCUSSION}

This study was carried out to investigate the effect of the OSTRC Shoulder Injury Prevention Program on the glenohumeral range of motion and upper extremity functional performance in adolescent throwers. As a result of the study, it was determined that the OSTRC Shoulder Injury Prevention Program, as an addition to the training programs for eight weeks, increased the IR range of motion on the dominant side and upper extremity functional performance but had no significant effect on other parameters. To the authors' knowledge, this is the first 
study to demonstrate the effectiveness of the OSTRC Shoulder Injury Prevention Program in adolescent throwers.

The range of motion of the glenohumeral joint is an important parameter to prevent shoulder injuries and to monitor post-injury rehabilitation [14]. Increased ER and reduced IR during throwing causes tension in the posterior capsule, leading to an increase in anterior translation and disintegration force during glenohumeral flexion. In addition, repeated eccentric stress on the rotator cuff due to excessive ER may lead to injuries by causing microtrauma in the tendons [2]. Structural adaptations in bone and soft tissues due to excessive forces on the shoulder during throwing are responsible for deficits in the range of motion [15]. The repeated deceleration phase results in a strained posterior capsule, leading to a limited glenohumeral IR range of motion, which can be critical for shoulder integrity [16]. IR loss of range of motion is a known risk factor for chronic shoulder pain [17]. For all these reasons, exercises to increase the reduced IR range of motion should be added to training programs.

For throwers, providing the necessary torque and power to throw heavy equipment over a long distance requires extreme force, balance, coordination, timing, and flexibility. To be a successful thrower, it is necessary to maintain flexibility to withstand difficult positions while maintaining the strength to generate torque and leverage. Throwers must take unusual positions (such as the power position in shot put) that require tremendous flexibility to perform properly. Therefore, it has been reported in previous studies that flexibility exercises, such as shoulder internal rotators, hip flexors, hamstrings and abdominal rotators, should be included in the training programs of throwers [1]. Our study investigated the effect of the OSTRC Shoulder Injury Prevention Program, which is used to increase the IR range of motion, on the glenohumeral range of motion in throwers. At the end of the study, it was determined that this program improved the dominant side IR range of motion in throwers. Although not statistically significant, an increase in the IR range of motion of the nondominant side was also observed. However, there was no significant difference in ER and the total range of motion between the pre-test and the post-test. There are several studies in the literature which investigate the effects of training programs on the range of motion in different sports disciplines. Fredriksen and Myklebust investigated the effect of the OSTRC Shoulder Injury Prevention Program on handball players' range of motion and stated that it had no effect on IR, ER and the total range of motion [8]. Oranchuk et al. also investigated the effect of an eight-week sports-specific training program with resistance bands and general training program on the glenohumeral range of motion in softball players, and at the end of the study, they found that both training programs did not cause a statistically significant difference on the ER and IR range of motion [18]. Moore et al. applied a 2-stage strengthening program in 14 baseball players for 20 weeks before the season and found that the glenohumeral joint IR and total range of motion remained the same. The reason for the lack of a difference in the IR range of motion in the study was attributed to the absence of specific stretching exercises in the program [19]. The lack of a difference in the ER and total range of motion in the study by Fredriksen and Myklebust, in the ER values in the study by Oranchuk et al. and in the total range of motion in the study by Moore et al. supports the results of our study. However, unlike these studies, it was observed that there was a difference in the glenohumeral joint IR range of motion after the program applied in our study. The difference in our results in terms of the IR range of motion may be caused by the fact that the athletes are engaged in different disciplines. In addition, the OSTRC Shoulder Injury Prevention Program used in our study included "sleeper stretch" and "crossbody stretch" exercises, which are stretching exercises aimed at increasing the IR range of motion. These exercises are the most commonly used exercises to increase the IR range of motion [20]. We believe that the reason for the increase in the IR range of motion in our study is due to these specific exercises. 
Functional tests for the upper extremity provide objective information about activities during sports. Several tests have been developed for this purpose; the most widely used one is CKCUEST [21]. CKCUEST is a simple, valid and low-cost test that can be easily applied in a clinical or sports context and shows high correlation with muscle strength measurements [22]. This test evaluates the function and stability of the upper extremity. It is used in the literature in order to identify risk factors for shoulder pain [23], to determine the effectiveness of different types of intervention [24] and to predict the development of throwing distances $[22,25]$. In addition, this test can be used to compare athletes and to determine if they can return to sports. The advantage of this functional test is that it provides valuable information on how the athlete uses an upper extremity in several ways (strength, speed and stabilization) in a challenging position [21]. As a result of our study, it was observed that CKCUEST scores, which evaluate upper extremity functional performance, increased following the OSTRC Shoulder Injury Prevention Program. It is expected that this injury prevention program, which includes exercises to increase the strength, stability and proprioception of the upper extremity, will increase the CKCUEST score, which evaluates the function and stability of the upper extremity. Also, this could be the result of the "trunk rotation" and its advanced version of the "plank with passing" included in the program. The positions of these exercises are similar to the position and method of the test used to evaluate upper extremity functional performance in our study. These exercises, which were performed in a position similar to the test, may have caused an increase in performance both by increasing the stability of the upper extremities and by repeating the same position for 8 weeks. Based on the results of this study, although our study has shown that the OSTRC Shoulder Injury Prevention Program improves the upper extremity functional performance, no comparison could be made as there is no study in the literature which investigate this effect in adolescent throwers.

\section{LIMITATIONS}

Some limitations of this study must be acknowledged. First, the sample size was small due to the low number of throwers. To generalize the findings of this study, a larger cohort of subjects is needed. Second, the current study lacked a control or comparison group. As there is no previous study of the effects of the OSTRC Shoulder Injury Prevention Program on adolescent throwers, this pilot study was conducted to observe the OSTRC Shoulder Injury Prevention Program. Future studies must include a control group continuing their routine training program. Third, although there are studies showing that this program has an effect on the strength of the external rotator and internal rotator muscles, this study could not evaluate the strength. Further studies are needed to look at the effect of this program on the rotator cuff muscle strength in throwers.

\section{CONCLUSION}

As a result of this study, which investigated the effect of the OSTRC Shoulder Injury Prevention Program on the glenohumeral range of motion and upper extremity functional performance for the first time in throwers, it was observed that the program improved the IR range of motion and upper extremity functional performance. More research is needed to investigate the effects of the OSTRC Shoulder Injury Prevention Program on injury risk factors, such as range of motion, strength and scapular dyskinesia and sportive performance in different branches.

\section{ACKNOWLEDGMENTS}

The authors would like to thank Yusuf Demirkan, Berk Aras and Asya Çiftçi for their assistance in the study. 


\section{REFERENCES}

[1] Meron A, Saint-Phard D. Track and field throwing sports: injuries and prevention. Curr Sports Med Rep 2017;16(6):391-6 https://doi.org/10.1249/JSR.0000000000000416

[2] Kim H, Lee Y, Shin I, Kim K, Moon J. Effects of 8 weeks' specific physical training on the rotator cuff muscle strength and technique of javelin throwers. J Phys Ther Sci. 2014;26(10):1553-6. https://doi.org/10.1589/jpts.26.1553

[3] Setayesh K, Mayekar E, Schwartz B. Upper extremity injuries in field athletes: Targeting 512 injury prevention. Annals of sports medicine and research. 2017;4(1):1098.

[4] Edouard P, Depiesse F, Serra J-M. Throwing arm injuries in high-level athletics throwers. Sci Sports 2010;25(6):318-22. https://doi.org/10.1016/j.scispo.2010.08.004

[5] Edouard P, Damotte A, Lance G, Degache F, Calmels P. Static and dynamic shoulder stabilizer adaptations in javelin throwers: A preliminary study. Isokinet Exerc Sci. 2013;21(1):47-55. https://doi.org/10.3233/IES-2012-0470

[6] Asker M, Brooke HL, Waldén M, et al. Risk factors for, and prevention of, shoulder injuries in overhead sports: A systematic review with best-evidence synthesis. BrJ Sports Med. 2018;52(20):1312-9. https://doi.org/10.1136/bjsports-2017-098254

[7] Andersson SH, Bahr R, Clarsen B, Myklebust G. Preventing overuse shoulder injuries among throwing athletes: A cluster-randomised controlled trial in 660 elite handball players. Br J Sports Med. 2017;51(14):1073-80. https:// doi.org/10.1136/bjsports-2016-096226

[8] Fredriksen H, Cools A, Bahr R, Myklebust G. Does an effective shoulder injury prevention program affect risk factors in handball? A randomized controlled study. Scand J Med Sci Sports. 2020; 30(8):1423-1433. https://doi.org/10.1111/sms.13674

[9] Andersson SH, Bahr R, Olsen MJ, Myklebust G. Attitudes, beliefs, and behavior toward shoulder injury prevention in elite handball: Fertile ground for implementation. Scand J Med Sci Sports. 2019;29(12):1996-2009. https://doi. org/10.1111/sms.13522

[10] Wilk KE, Reinold MM, Macrina LC, Porterfield R, Devine KM, Suarez K, et al. Glenohumeral internal rotation measurements differ depending on stabilization techniques. Sports Health. 2009;1(2):131-6. https://doi. org/10.1177/1941738108331201

[11] de Oliveira VM, Pitangui AC, Nascimento VY, da Silva HA, Dos Passos MH, de Araújo RC. Test-retest reliability of the closed kinetic chain upper extremity stability test (CKCUEST) in adolescents: reliability of CKCUEST in adolescents. Int J Sports Phys Ther. 2017;12(1):125.

[12] Lee D-R, Kim LJ. Reliability and validity of the closed kinetic chain upper extremity stability test. J Phys Ther Sci. 2015;27(4):1071-3. https://doi.org/10.1589/jpts.27.1071

[13] Cohen J. Statistical power analysis for the behavioral sciences: Academic Press; 2013. https://doi.org/10.4324/9780203771587

[14] Roetert EP, Ellenbecker TS, Brown SW. Shoulder internal and external rotation range of motion in nationally ranked junior tennis players: a longitudinal analysis. J Strength Cond Res. 2000;14(2):140-3. https://doi.org/10.1519/00124278200005000-00004

[15] Bailey LB, Thigpen CA, Hawkins RJ, Beattie PF, Shanley E. Effectiveness of manual therapy and stretching for baseball players with shoulder range of motion deficits. Sports Health. 2017;9(3):230-7. https://doi. org/10.1177/1941738117702835

[16] Gillet B, Begon M, Diger M, Berger-Vachon C, Rogowski I. Shoulder range of motion and strength in young competitive tennis players with and without history of shoulder problems. Phys Ther Sport. 2018;31:22-8. https://doi.org/10.1016/j. ptsp.2018.01.005

[17] Cools AM, Johansson FR, Borms D, Maenhout A. Prevention of shoulder injuries in overhead athletes: a science-based approach. Braz J Phys Ther. 2015;19(5):331-9. https://doi.org/10.1590/bjpt-rbf.2014.0109

[18] Oranchuk DJ, Ecsedy EN, Robinson TL. Effects of a sport-specific upper-body resistance-band training program on overhead throwing velocity and glenohumeral joint range of motion. J Strength Cond Res. 2021;35(11): 3097-3103. https://doi.org/10.1519/JSC.0000000000003303

[19] Moore SD, Uhl TL, Kibler WB. Improvements in shoulder endurance following a baseball-specific strengthening program in high school baseball players. Sports Health. 2013;5(3):233-8. https://doi.org/10.1177/1941738113477604

[20] Mine K, Nakayama T, Milanese S, Grimmer K. Effectiveness of stretching on posterior shoulder tightness and glenohumeral internal-rotation deficit: a systematic review of randomized controlled trials. J Sport Rehabil. 2017;26(4):294-305. https://doi.org/10.1123/jsr.2015-0172

[21] Pontillo M, Spinelli BA, Sennett BJ. Prediction of in-season shoulder injury from preseason testing in division I collegiate football players. Sports Health. 2014;6(6):497-503. https://doi.org/10.1177/1941738114523239

[22] Silva YA, Novaes WA, Dos Passos MHP, Nascimento VYS, Cavalcante BR, Pitangui ACR, et al. Reliability of the Closed Kinetic Chain Upper Extremity Stability Test in young adults. Phys Ther Sport. 2019;38:17-22. https://doi org/10.1016/j.ptsp.2019.04.004

[23] Tate A, Turner GN, Knab SE, Jorgensen C, Strittmatter A, Michener LA. Risk factors associated with shoulder pain and disability across the lifespan of competitive swimmers. J Athl Train. 2012;47(2):149-58. https://doi.org/10.4085/1062 6050-47.2.149

[24] Lust KR, Sandrey MA, Bulger SM, Wilder N. The effects of 6-week training programs on throwing accuracy, proprioception, and core endurance in baseball. J Sport Rehabil. 2009;18(3):407-26. https://doi.org/10.1123/jsr.18.3.407

[25] Negrete RJ, Hanney WJ, Kolber MJ, Davies GJ, Riemann B. Can upper extremity functional tests predict the softball throw for distance: A predictive validity investigation. Int J Sports Phys Ther. 2011;6(2):104.

Cite this article as:

Cobanoglu G, Aka H, Guzel NA.

The effect of shoulder injury prevention program on glenohumeral range of motion and upper extremity performance in adolescent throwers:

A pilot study

A pilot study
Balt J Health Phys Act. 2021;13(4):9-15

doi: 10.29359/BJHPA.13.4.02 